\title{
Outcome of Phyllodes Tumors of the Breast: A series of Consecutive cases
}

\author{
Parham Khosravi-Shahii ${ }^{1 *}$, Sara Custodio-Cabello ${ }^{2}$, Magda Palka-Kotlowska², and Luis Cabezón-Gutiérrez² \\ ${ }^{1}$ Department of Medical Oncology, Hospital General Universitario Gregorio Marañón, Spain \\ ${ }^{2}$ Service of Medical Oncology, Torrejón University Hospital, Spain
}

Submission: February 10, 2021; Published: February 24, 2021

*Corresponding author: Parham Khosravi-Shahi, Medical Oncology Service, Hospital General Universitario Gregorio Marañón, Doctor Esquerdo Street, 46, 28007, Madrid, Spain

\section{Abstract}

Background: Phyllodes tumor of the breast (PTB) is a rare tumor. PTB exist in benign (BPTB), borderline, and malignant (MPTB) subtypes. Local recurrence (LR) is the most common site of relapse. Treatment of early-stage PTB consists of local excision (LE), with free margins of resection (MR) or mastectomy (MM)

Patients and Methods: We conducted a retrospective study of all consecutive patients with early-stage PTB treated with breast surgery at our institution for 8 years, in order to describe the outcome and the clinical behavior of PTB. The primary end-points of our study were diseasefree survival (DFS) and overall survival (OS). Secondary endpoints were the description of the pathological features, the site of first recurrence (SFR), and prognostic factors.

Results: We included a total of 16 patients. Four patients had BPTB, and 12 had MPTB. Median age was 50 years (21-81), and 62.5\% was postmenopausal. Five patients (31.25\%) were treated with LE and 11 (68.75\%) with MM. Median tumor size was 3.6 cm (1.3-19), median mitosis/high-power field was 10 and $6.25 \%$ had positive-MR. With a median follow-up of 97 months, 5-year DFS probability was $65 \%$. There were 5 recurrences (31.25\% of all patients), all of them in the malignant subtype. 5 -year OS probability was $66 \%$. The most common SFR was LR $(62.5 \%)$, followed by lung $(18.75 \%)$ and bone $(18.75 \%)$ metastases. In univariate analysis, $\mathrm{T}>4.5 \mathrm{~cm}(\mathrm{p}=0.004)$ and positive-MR ( $\mathrm{p}=0.038)$ were associated with an increased risk of relapse and death.

Conclusion: BPTB is associated with a good prognosis after adequate surgery. However, MPTB has a high risk of relapse and death after surgery, and this risk increases with larger tumors and positive-MR.

Keywords: Phyllodes tumors; Local recurrence; Local excision; Malignant subtype

\section{Introduction}

Phyllodes tumors of the breast (PTB), also termed phylloides tumors, are rare tumors ( $<0.5 \%$ of all breast tumors), comprised of both stromal and epithelial elements. These tumors occur in an older age distribution than fibroadenoma, and a younger age distribution than the invasive lobular and ductal carcinomas of the breast; and the median age at diagnosis is about 45 years. Some case reports describe these tumors in men, usually in association with ginecomastia [1-3].

Tumor size is variable, ranging from 1 to $41 \mathrm{~cm}$ (median 4 to $7 \mathrm{~cm}$ ). As they grow, РТB can distort the breast or cause skin ulceration through pressure necrosis. PTB have a diverse range of biologic behavior, from benign forms to variants that metastasize distantly, and sometimes dedifferentiate histologically into a sarcomatous lesion that lacks an epithelial component. Traditionally, PTB are graded by the use of a set of histologic features into benign, borderline, and malignant $[4,5]$. As described in most series, all PTB may recur, but only the borderline and malignant tumors metastasize. Diagnosis of PTB prior to excisional biopsy or lumpectomy is uncommon, since it is indistinguishable from a fibroadenoma on mammography, breast magnetic resonance imaging or ultrasound and is difficult to distinguish from fibroadenomas on both fine needle aspiration and core biopsy. Treatment of early-stage PTB consists of local surgical excision with tumor free margins of $1 \mathrm{~cm}$ or greater [6]. Lumpectomy or partial mastectomy is the preferred surgical 
therapy. Total mastectomy is recommended if negative margins cannot be obtained by conservative surgery. Surgical axillary staging or axillary lymph node dissection is not recommended, since PTB rarely metastasize to axillary lymph nodes. Only in patients with pathologic nodes on clinical examination the axillary node dissection is necessary. Adjuvant therapies (radiotherapy and chemotherapy) have no clearly defined role in the treatment of PTB, and should be more carefully investigated so that treatment approaches can be tailored to the individual patient [7-10].

Given their rarity, epidemiologic data are scant. For this reason, we carried out a study in order to describe the outcome and the clinical behavior of consecutive cases of early-stage PTB treated with surgery in our hospital for 8 years $[11,12]$.

\section{Patients and Methods}

\section{Study Design and Eligibility Criteria of Patients}

We conducted a retrospective observational study in order to analyze the outcome and the clinical behavior of this tumor in all consecutive patients with an early-stage PTB treated with surgery at our institution for 8 years. Eligible patients were at least 18 years of age, had a histologically confirmed PTB, had nonmetastatic PTB, were treated with breast surgery (local surgical excision or mastectomy) and were treated in our Hospital between January of 2000 and December of 2008 . Hence, we included in this study all consecutive cases of patients with early-stage PTB, who had all eligibility criteria and provided informed consent.

\section{Study end-points}

The primary end-points of our study were disease-free survival (DFS) and overall survival (OS). DFS was defined as the time from the date of breast surgery until the date of the first occurrence of one of the following events: an ipsilateral local recurrence, a distant disease recurrence (distant metastasis) or death from any cause. OS was defined as the time from the diagnosis of PTB until death from any cause. Secondary endpoints were the description of the pathological features, the site of first recurrence, and prognostic factors.

\section{Statistical Analysis}

Standard summary statistics for continuous variables were: median, range, standard deviation and/or 95\% confidence interval $(95 \% \mathrm{CI})$. Standard summary statistics for discrete variables were: count and proportion. Survival estimations (DFS and OS) were calculated with Kaplan-Meier methods. The stata statistical program, version 14 (StataCorp. 2007. Stata Statistical Software: Release 14. College Station, TX: StataCorp LP) was used for all statistical analyses.

\section{Results}

In our study, we included a total of 16 consecutive patients with early-stage PTB and all of them (100\%) were women. Four patients (25\%) had a benign tumor, and 12 patients $(75 \%)$ had a malignant PTB. Median age was 50 years (range 21-81) and $62.5 \%(10 / 16)$ of the patients was postmenopausal. In our study, 5 patients $(31.25 \%)$ were treated with local excision and 11 patients $(68.75 \%)$ with mastectomy. With a median follow-up of 97 months (95\%CI: 91-103), median DFS was not reached, and the probability of DFS at 5 years was $65 \%$ (Figure 1). In this study, there were five recurrences ( $31.25 \%$ of all patients had a relapse), all of them in the malignant subgroup. Hence, 100\% (4/4) of patients with benign PTB were alive without any events. In the malignant subgroup (12/16), 5-year DFS probability was 50\% and median DFS was 60 months (95CI\%: 53-68).

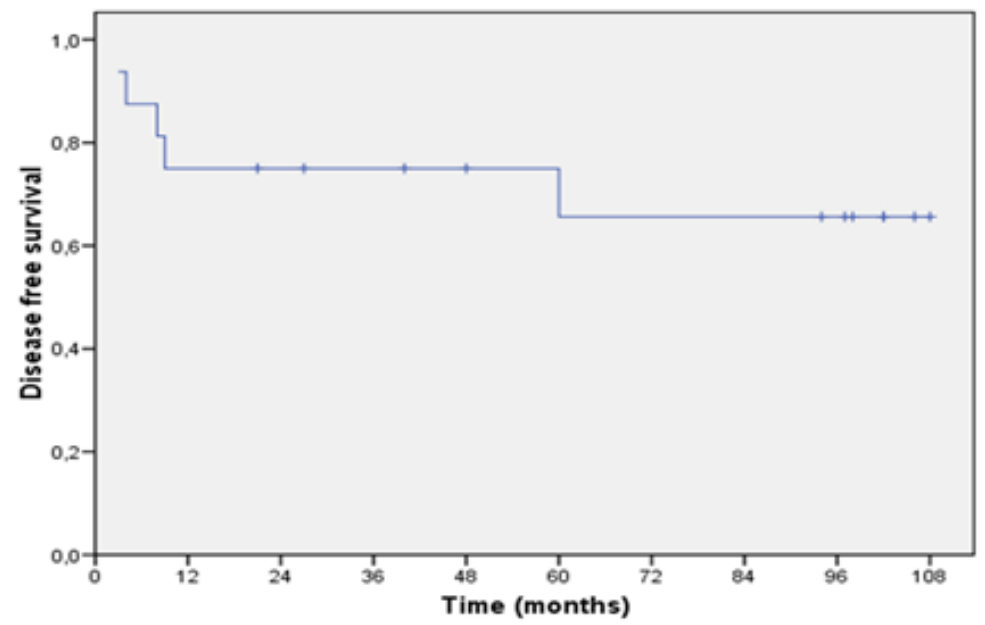

Figure 1: Kaplan-Meier estimates of disease-free survival (DFS).

In the entire population of the study $(n=16)$, with a median follow-up of 97 months (95\% Cl: $91-103$ months), median DFS was not reached and 5 -year DFS probability was $65 \%$. There were five recurrences, all of them in the patients with malignant phyllodes tumor of the breast. 


\section{Cancer Therapy \& Oncology International Journal}

In our study, there were five deaths (31.25\% of all patients), all of them in the malignant subgroup: 4 patients died due to disease progression and 1 patient due to a sepsis related to treatment. Median OS was not reached in the entire population and 5-year OS probability was $66 \%$ (Figure 2). With respect to the pathological features, $93.75 \%(15 / 16)$ of the patients had an unifocal tumor, median tumor size was $3.6 \mathrm{~cm}$ (range 1.3-19) and 31.25\% (5/16) of the patients had a tumor size equal or higher than $4.5 \mathrm{~cm}$ (Table 1). Median mitosis/high-power field (HPF) was 10, $62.5 \%(10 / 16)$ of the patients had more than 10 mitosis/HPF, 31.25\% (5/16) had tumor necrosis in the surgical specimen, $18.75 \%(3 / 16)$ of the patients had a skin infiltration in the surgical specimen, and $6.25 \%(1 / 16)$ had positive margins of resection.

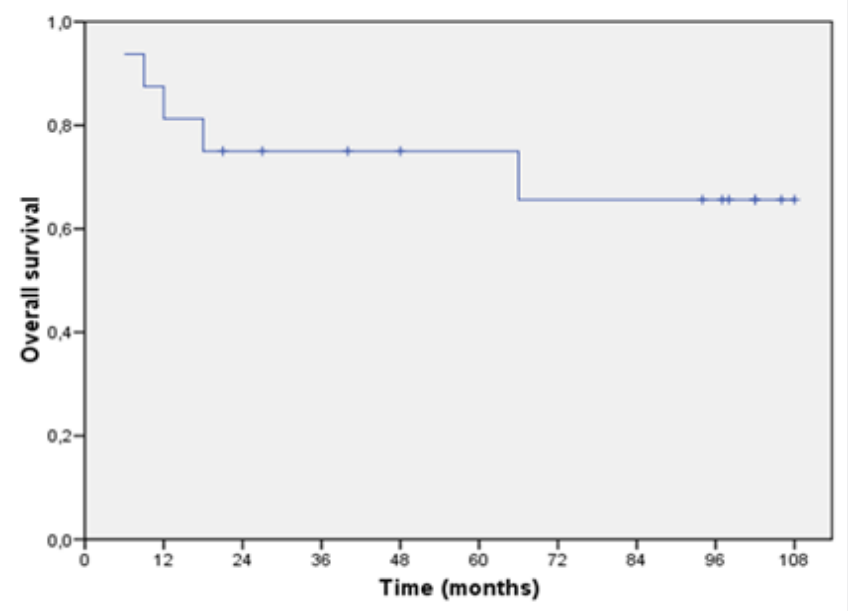

Figure 2: Kaplan-Meier estimates of overall survival (OS).

In the entire population of the study ( $n=16)$, with a median follow-up of 97 months (95\% Cl: $91-103$ months), median OS was not reached and 5 -year OS probability was $66 \%$. There were five deaths, all of them in the patients with malignant phyllodes tumor of the breast.

Table 1: Pathological characteristics of the entire population of the study $(n=16)$.

\begin{tabular}{|c|c|}
\hline \multicolumn{2}{|c|}{ Pathological Characteristic } \\
\hline Unifocal tumor, n (\%) & $15(93.75 \%)$ \\
\hline $\begin{array}{l}\text { Tumor size, median (range) } \\
\text { Tumor size } \geq 4.5 \mathrm{~cm}, \mathrm{n}(\%)\end{array}$ & $\begin{array}{c}3.6 \mathrm{~cm}(1.3-19) \\
5(31.25 \%)\end{array}$ \\
\hline $\begin{array}{l}\text { Mitosis/high-power field (HPF): } \\
\text { Median } \\
\geq 10 \text { mitosis/HPF, n (\%) }\end{array}$ & $\begin{array}{c}10 \\
10(62.5 \%)\end{array}$ \\
\hline $\begin{array}{c}\text { Tumor necrosis: } \\
\text { Yes, n (\%) } \\
\text { No, n (\%) }\end{array}$ & $\begin{array}{c}5(31.25 \%) \\
11(68.75 \%)\end{array}$ \\
\hline $\begin{array}{l}\text { Skin infiltration: } \\
\text { Yes, n (\%) } \\
\text { No, n (\%) }\end{array}$ & $\begin{array}{c}3(18.75 \%) \\
13(81.25 \%)\end{array}$ \\
\hline $\begin{array}{l}\text { Margins of resection: } \\
\text { Yes, } \mathrm{n}(\%) \\
\text { No, } \mathrm{n}(\%)\end{array}$ & $\begin{array}{c}1(6.25 \%) \\
15(93.75 \%)\end{array}$ \\
\hline
\end{tabular}

The most common site of first recurrence was local recurrence in the ipsilateral breast $(62.5 \% ; 10 / 16)$, followed by lung $(18.75 \%$; $3 / 16)$ and bone $(18.75 \% ; 3 / 16)$ metastases. In univariate analysis, tumor size equal or higher than $4.5 \mathrm{~cm}(\mathrm{p}=0.004)$ and positivemargin $(p=0.038)$ were adverse prognostic factors, associated with an increased risk of relapse and death. Neither age nor menstrual status or tumor necrosis or number of mitosis or type of surgery were associated with a significant increase in relapse.

\section{Discussion}

PTB are very rare tumors, accounting for less than $0.5 \%$ of all breast tumors. These tumors are comprised of both stromal and epithelial elements; and traditionally they are graded by the use of a set of histologic data into benign, borderline, and malignant subtypes. Unfortunately, the histologic classification of PTB does not reliably predict clinical behavior. Given the rarity of PTB, 


\section{Cancer Therapy \& Oncology International Journal}

epidemiologic data are scant. Thus, we conducted this study to describe the outcome and the clinical behavior of early-stage PTB treated with surgery in our hospital.

In our study, with a median follow-up of 8 years, median DFS was not reached in the entire population, and 5-year DFS probability was $65 \%$. There were five recurrences $31.25 \%$ of all patients), all of them in the malignant subgroup (12/16; 75\% of the patients), and all these patients with a relapse died, mostly due to the tumor progression. Thus, all patients with benign PTB were alive without any events at the time of the study analysis (5year DFS probability of $100 \%$ ). In the malignant subgroup, 5-year DFS probability was $50 \%$ and median DFS was 60 months.

There were five deaths in our study, all of them in the malignant subgroup: 4 patients died due to disease progression and 1 patient due to a sepsis related to treatment. Median OS was not reached in the entire population and 5-year OS probability was $66 \%$. Hence, in this study malignant subtype of PTB was associated with poorer prognosis after breast surgery, with an absolute risk of recurrence and death of $35 \%$.

In our study, the most common site of first recurrence was local recurrence in the ipsilateral breast (62.5\%), followed by lung $(18.75 \%)$ and bone $(18.75 \%)$ metastases. In univariate analysis, tumor size equal or higher than $4.5 \mathrm{~cm}(\mathrm{p}=0.004)$ and positivemargin $(p=0.038)$ were adverse prognostic factors, associated with an increased risk of relapse and death. Neither age nor menstrual status or tumor necrosis or number of mitosis or type of surgery were associated with a significant increase in relapse. Similar data to our study have been published in the literature. Despite the complete surgical resection of the primary tumor up to $30 \%$ of early-stage PTB have local failure; and in approximately $25 \%$ of cases, malignant PTB may give rise to hematogenous metastases. The most frequent sites of distant metastases are the lungs followed by soft tissue, bone, and pleura. Several predictive factors of recurrence and metastases have been described. One of the most important risk factor associated with local recurrence is an inadequate surgery. Surgical margins $<1 \mathrm{~cm}$ are associated with the highest risk of local recurrence.

In the study conducted by Chen et al, age, surgical approach, mitotic activity, and surgical margin were significantly correlated with recurrence ( $p=0.03,0.02,0.048$, and $<0.001$, respectively); and stromal cellularity, stromal overgrowth, stromal atypia, mitotic activity, tumor margin, and heterologous stromal elements were significantly correlated with metastases $(\mathrm{p}=0.032,<0.001$, $<0.001,0.004,0.005$, and 0.046 , respectively). Other studies have suggested that tumor necrosis is also linked to an increased risk of local recurrence. In the M.D. Anderson series of 101 patients, 8 patients developed distant metastases. Overall survival in the series was $62 \%$ at 15 years. For patients with non-malignant (benign or borderline) and malignant PTB, the overall survival was $79 \%$ and $42 \%$, respectively, at 10 years. Multivariate analysis using Cox proportional hazards regression revealed stromal overgrowth to be the only independent predictor of distant failure in this series. Other factors implicated as having an increased risk of metastatic development include large tumor size, infiltrative borders, necrosis, and increased mitotic index 4 .

\section{Conclusion}

In summary, in our study benign early-stage PTB was associated with a good prognosis after adequate surgery. However, malignant early-stage PTB had a high risk of relapse and death after surgery, and this risk increases with higher tumor size $(>4.5 \mathrm{~cm})$ and positive margins of resection. In this subgroup of patients, the value of adjuvant chemotherapy and/or radiation should be tested in multicenter, prospective, randomized trials; because despite the complete surgical resection, local failure rate may be high for malignant tumors; and a quarter of patients with malignant PTB may give rise to hematogenous metastases.

\section{Conflict of Interest}

The authors declare that they have no conflict of interest.

\section{References}

1. Reinfuss M, Mitus J, Duda K, J Ryś, K Smolak (1996) The treatment and prognosis of patients with phyllodes tumor of the breast: An analysis of 170 cases. Cancer 77: 910-916.

2. Bernstein L, Deapen D, Ross RK (1993) The descriptive epidemiology of malignant cystosarcoma phyllodes tumors of the breast. Cancer 71: 3020-3024

3. Anderson BO, Lawton TJ, Lehman CD, Moe RE (2004) Phyllodes Tumors. In: Diseases of the Breast, 3rd ed, Harris, JR, Lippman, ME, Morrow, M, Osborne, CK (Eds), Lippincott Williams \& Wilkins, Philadelphia, USA, pp. 669.

4. Chaney AW, Pollack A, McNeese MD, G K Zagars, P W Pisters, et al. (2000) Primary treatment of cystosarcoma phyllodes of the breast. Cancer 89(7): 1502-1511.

5. Tavassoli FA \& Devilee P (2003) Pathology and genetics of tumours of the breast and female genital organs. In: World Health Organization Classification of Tumours. Lyons, IARC Press, p. 99-103.

6. Salvadori B, Cusumano F, Del Bo R, V Delledonne, M Grassi, et al. (1989) Surgical treatment of phyllodes tumors of the breast. Cancer 63(12): 2532-2536.

7. Stebbing JF, Nash AG (1995) Diagnosis and management of phyllodes tumour of the breast: experience of 33 cases at a specialist centre. Ann R Coll Surg Engl 77(3): 181-184.

8. Khosravi-Shahi P (2011) Management of non metastatic phyllodes tumors of the breast: review of the literature. Surg Oncol 20(4): e143148.

9. Yagishita M, Nambu Y, Ishigaki M, T Okada, K Yamanouchi, et al. (1999) Pulmonary metastatic malignant phyllodes tumor showing multiple thin walled cavities. Nihon Kokyuki Gakkai Zasshi 37(1): 61-66.

10. Chen WH, Cheng SP, Tzen CY, Tsen-Long Yang, Kuo-Shyang Jeng, et al. (2005) Surgical treatment of phyllodes tumors of the breast: retrospective review of 172 cases. J Surg Oncol 91(3): 185-194. 


\section{Cancer Therapy \& Oncology International Journal}

11. Barrio AV, Clark BD, Goldberg JI, Laura W Hoque, Stephanie F Bernik, et al. (2007) Clinicopathologic features and long-term outcomes of 293 phyllodes tumors of the breast. Ann Surg Oncol 14(10): 2961-2970.
12. Moffat CJ, Pinder SE, Dixon AR, C W Elston, R W Blamey, et al. (1995) Phyllodes tumours of the breast: a clinicopathological review of thirtytwo cases. Histopathology 27(3): 205-218.
This work is licensed under Creative Commons Attribution 4.0 License

DOI:10.19080/CTOIJ.2021.18.555980
Your next submission with Juniper Publishers will reach you the below assets

- Quality Editorial service

- Swift Peer Review

- Reprints availability

- E-prints Service

- Manuscript Podcast for convenient understanding

- Global attainment for your research

- Manuscript accessibility in different formats ( Pdf, E-pub, Full Text, Audio)

- Unceasing customer service

Track the below URL for one-step submission https://juniperpublishers.com/online-submission.php 